\title{
REFLEXÕES ACERCA DOS PRINCÍPIOS DA POLÍTICA NACIONAL DE ENFRENTAMENTO À VIOLÊNCIA CONTRA AS MULHERES E SUA CORRELAÇÃO COM A ATUAÇÃO DO ENFERMEIRO
}

\author{
F. E. A. FEITOSA ${ }^{1}$, B. DE C. MAGALHÃES ${ }^{2}$, P. P. T. DE ALCANTARA ${ }^{3}$ \\ Universidade Regional do Cariri \\ ORCID ID: https://orcid.org/0000-0003-0420-0977 ${ }^{1}$ \\ franciscaeaf@hotmail.com ${ }^{1}$
}

Submetido 29/02/2020 - Aceito 07/08/2020

DOI: 10.15628/holos.2020.9609

\section{RESUMO}

Com altas taxas de incidência e morbimortalidade, assim como diversos danos causados a saúde individual e coletiva a Violência Contra a Mulher constitui um importante problema de saúde pública no Brasil. Assim, este estudo objetiva refletir criticamente a aplicabilidade dos princípios da Política Nacional de Enfrentamento à Violência Contra as Mulheres dentro da atuação do Enfermeiro na Atenção Primária à Saúde. A análise crítico-reflexiva da atuação do enfermeiro possibilitou a identificação de categorias temáticas referentes a cada princípio, sendo eles: a) Igualdade e Respeito à diversidade; b) Equidade; c) Autonomia das mulheres; d) Laicidade do Estado; e) Universalidade das Políticas; f) Justiça Social; g) Transparência dos atos públicos; e h) Participação e Controle Social. Nesse sentido, destaca-se o quanto foi inovador fazer essa correlação entre os princípios da política, assistência à saúde e a literatura científica. Logo, acredita-se que este estudo contribua para fomentar novas discussões e pesquisas acerca da problemática de enfrentamento da VCM.

PALAVRAS-CHAVE: Atenção Primária a Saúde, Cuidados de Enfermagem, Saúde pública, Violência contra a Mulher.

\section{REFLECTIONS ABOUT THE PRINCIPLES OF THE NATIONAL POLICY TO COMBAT VIOLENCE AGAINST WOMEN AND THEIR CORRELATION WITH NURSES 'PERFORMANCE}

\section{ABSTRACT}

With high rates of incidence and morbidity and mortality, as well as several damages caused to individual and collective health, Violence Against Women is an important public health problem in Brazil. Thus, this study aims to critically reflect the applicability of the principles of the National Policy to Combat Violence Against Women within the role of the Nurse in Primary Health Care. The critical-reflexive analysis of the role of the nurse enabled the identification of thematic categories referring to each principle, which are: a) Equality and Respect for diversity; b) Equity; c) Women's autonomy; d)
\end{abstract}

Secularity of the State; e) Universality of Policies; f) Social Justice; g) Transparency of public acts; and h) Participation and Social Control. In this sense, it is highlighted how innovative it was to make this correlation between the principles of politics, health care and scientific literature. Therefore, it is believed that this study contributes to foster new discussions and research on the problem of coping with CMV.

KEYWORDS: Primary Health Care, Nursing Care, Public Health, Violence against Women 


\section{INTRODUÇÃO}

A Violência Contra à Mulher (VCM) constitui um importante problema de saúde pública no Brasil, onde existe uma alta incidência, danos à saúde individual e coletiva e alta taxa de morbimortalidade. É definida pela Lei 11.340, de 7 de agosto de 2006, intitulada Lei Maria da Penha, como qualquer ação ou omissão baseada no gênero que the cause morte, lesão, sofrimento físico, sexual ou psicológico e dano moral ou patrimonial (Brasil, 2006; Menezes, 2014; Garbin, Dias, Rovida \& Garbin, 2015).

Vale salientar que esse tipo de violência é socialmente construída, tendo em vista o espaço social de dominação masculina e submissão feminina criada pelo patriarcado e pelas diferenças de gênero. Nesse contexto, expõe-se que como forma de combater a violência contra a mulher, a comunidade internacional estabeleceu os Objetivos de Desenvolvimento do Milênio (ODS), que devem ser atingidos até 2030, no qual um dos objetivos visa alcançar à igualdade entre os sexos e a autonomia das mulheres (Lira; Barros, 2015; Cortes, Padoin, Vieira, Landerdahl \& Arboit, 2015).

Dada a complexidade da violência, sua prevenção e enfrentamento envolvem a conscientização e a participação efetiva de toda a sociedade, refletindo, assim, nos serviços de saúde. Requer, também, a articulação de políticas e ações na assistência integral da mulher (Menezes , 2014; Garbin et al., 2015).

Nesse sentido, destaca-se a Política Nacional para as Mulheres (2004) e a Política Nacional de Enfrentamento à Violência Contra as Mulheres (2011), que tem como objetivo enfrentar todas as formas de VCM a partir de uma perspectiva de gênero e de uma visão integral desse fenômeno (Brasil, 2011; Brasil, 2013).

Tendo em vista a Atenção Primaria à Saúde (APS) como porta de entrada para o atendimento à saúde da mulher, onde o enfermeiro mesmo sendo o profissional mais ligado à conjuntura do cuidar e do acolhimento com presença unânime em todo ciclo vital, ainda apresenta dificuldades diante da complexidade da violência. Logo, torna-se relevante a reflexão da atuação do enfermeiro dentro dos princípios da Política Nacional de Enfrentamento à Violência Contra as Mulheres, haja visto que os mesmos devem embasar a assistência à saúde da mulher. Assim, este estudo objetiva refletir criticamente a aplicabilidade dos princípios da Política Nacional de Enfrentamento à Violência Contra as Mulheres frente à atuação do Enfermeiro na APS.

\section{METODOLOGIA}

Trata - se de um estudo descritivo do tipo análise crítico-reflexiva que se embasa pelos princípios da Política Nacional de Enfrentamento à Violência Contra as Mulheres e pela atuação do enfermeiro na assistência à mulher vítima de violência na APS.

A análise crítico-reflexiva da atuação do enfermeiro possibilitou a identificação de categorias temáticas referentes a cada princípio, sendo eles: a) Igualdade e Respeito à diversidade; 
b) Equidade; c) Autonomia das mulheres; d) Laicidade do Estado; e) Universalidade das Políticas; f) Justiça Social; g) Transparência dos atos públicos; e h) Participação e Controle Social.

\section{RESULTADOS/DISCUSSÃO}

Mediante a análise crítico-reflexiva foi possível trazer a reflexão da aplicabilidade dos princípios da Política Nacional de Enfrentamento à Violência Contra as Mulheres (PNEVCM) dentro da atuação do Enfermeiro da Atenção Primária a Saúde (APS). As categorias abaixo ilustram os achados:

\subsection{Igualdade e Respeito à diversidade}

O primeiro princípio diz respeito à Igualdade e respeito à diversidade, em que mulheres e homens são iguais em seus direitos. A garantia da igualdade implica no respeito à diversidade cultural, étnica, racial, inserção social, situação econômica e regional, assim como os diferentes momentos da vida das mulheres (Brasil, 2011).

Sobre esse princípio, é importante ressaltar que a formação social do cidadão se baseia na imposição machista e nos pressupostos patriarcais, em que, desde os tempos mais remotos, a mulher é considerada um ser inferiorizado ao homem.

Assim, cabe reiterar a definição de violência contra a mulher estabelecida pela Organização Pan-americana de Saúde e pela Organização Mundial de Saúde em 2012, as quais especificam-na como qualquer ação que resulte em sofrimento físico, sexual e/ou psicológico, pautada em diferenças de gênero (OPAS, OMS, 2012).

Além disso, destaca-se que a violência contra a mulher possui caráter insidioso justamente em decorrência das desigualdades de gênero que atribui a mulher comportamentos pacifistas diante de abusos velados; inicia-se com pequenos atos violentos que vão se intensificando e se encobertando pela imagem protetora do homem, caracterizando o relacionamento abusivo, que não é percebido como tal pela mulher (Sousa et al., 2018).

Nesse contexto, é importante explanar sobre dificuldades que o enfermeiro percorre diante da complexidade da violência contra a mulher, que se dão tanto em decorrência da cultura patriarcal em que o enfermeiro foi criado enquanto ser social, como pelo déficit em abordagens críticas durante a graduação (Cordeiro et al., 2015; Silva et al., 2017).

As dificuldades assistenciais caracterizam-se por deficiência em encaminhamentos, desconhecimento, impotência na articulação e baixa resolutividade das redes de apoio; falta de tempo para atendimento adequado, pois priorizam-se outras situações e falta de habilidade para abordar a temática com o paciente (Cann et al., 2001; Visetin et al., 2015).

A desigualdade entre mulheres e homens dificilmente é percebida, tanto pelo enfermeiro como pela vítima, pois as mulheres devem ocupar o papel social de submissão ao pais, irmãos e companheiros, em que deve ser dócil, obediente, boa mãe e boa dona de casa; enquanto o homem é criado para trabalhar fora, ser o provedor da família, ser forte e corajoso e representar o ser 
dominante em uma relação. Dessa forma, a inserção social e os papéis de gênero atribuídos desde o nascimento, culminam para a desigualdade em sociedade inclusive durante a assistência a saúde.

\subsection{Equidade}

Com relação ao segundo princípio, a equidade, é garantida a todas as pessoas a igualdade em oportunidades, observando-se os direitos universais e as questões específicas das mulheres (Brasil, 2011).

Nesse princípio, reflete-se a necessidade de enfermeiros capacitados no que se refere a (des)construção dos preceitos sociais impostos às mulheres, posto que os mesmos as tornam vulneráveis à vitimização e à revitimização, caracterizando-se como determinantes na naturalização da violência contra a mulher. Assim, para que esse princípio seja contemplado na assistência à saúde, torna-se necessário o conhecimento dos profissionais acerca da Política Nacional de Educação Permanente em Saúde.

Salienta-se, nessa perspectiva que a educação trata-se de um mecanismo permanente que deve ser assegurado também para os profissionais, sendo preconizado pelo Ministério da Saúde através da educação permanente; associando humanização à valorização dos usuários, profissionais e gestores que é instrumentalizada, entre outras ações, pela troca e construção de saberes (Vieira, Erdman \& Andrade, 2013).

Assim, desde 2004 o SUS possui a Política Nacional de Educação Permanente em Saúde (PNEPS), regulada pela Portaria GM/MS $n^{\circ}$. 198, prezando pelas situações e necessidades cotidianas dos trabalhadores, as quais estimulam os conteúdos a serem tratados pela educação permanente, pois esta tem a intenção de promover mudanças na formação e no desenvolvimento dos profissionais da saúde (Brasil, 2004).

Assim, vale destacar que um dos erros nas capacitações em saúde estão na exclusão das experiências vividas pelos enfermeiros e a dualidade de seus papéis como profissionais e como integrantes da comunidade. Assim, para uma formação de enfermeiros eficazes no que concerne à violência contra a mulher, é essencial abordar atitudes e experiências desses profissionais como indivíduos, buscando a sensibilização para a problemática e desconstrução pessoal dos preceitos sociais; e então intervir no papel de profissional da saúde (Kim \& Motsei, 2002).

\subsection{Autonomia das mulheres}

O terceiro princípio se refere a autonomia das mulheres, em que o poder de decisão sobre suas vidas e corpos deve ser assegurado às mulheres, assim como as condições de influenciar os acontecimentos em sua comunidade e seu país (Brasil, 2011).

Esse é um princípio indispensável no combate à violência contra a mulher, visto que descontrói a ideia de submissão e adoração ao homem que é ensinada a mulher desde criança. Esse princípio reflete ainda a importância do empoderamento da mulher e, assim, adquirir autonomia sobre sua vida, não subjugando-se a determinações machistas. 
Com relação a esse princípio, é valido mencionar a perspectiva de Acosta et al. (2017), no que se refere o emprego de cautela no manejo da mulher vítima de violência, em que não se pode incentivar a saída da mulher de casa tendo em vista o potencial de exposição a novas agressões e a possível hipossuficiência financeira e familiar da vítima, o que quer dizer que junto a assistência em saúde deve haver meios que garantam a segurança da vítima, assim como instrumentalização e capacitação para tomada de decisões conscientes, e criação de grupos de apoio à mulher vítima de violência; potencializando a autonomia da mesma.

Além disso, algo importante na perspectiva da promoção da autonomia da mulher, é, inicialmente, a consulta de enfermagem para criação de vínculo e intimidade com a paciente, que são otimizados através da observação das expressões e falas da mesma, criação de campo visual olho-no-olho, bem como preservação da privacidade e de um ambiente no qual a mulher não seja interrompida. Além disso, os autores frisam a necessidade do acolhimento com empatia e escuta ativa qualificada, visando a construção da confiança na relação enfermeiro-paciente (Marques, Riquinho, Santos \& Vieira, 2017; Zuchi et al., 2018).

Vale destacar que o enfermeiro deve se embasar no código de ética, aplicando a beneficência, que diz respeito à obrigação moral de agir em benefício dos outros, avaliando-se os riscos; o princípio da não maleficência, que visa não causar mal e evitar danos às pessoas; o princípio da justiça, que busca o equilíbrio entre os deveres e os benefícios sociais; e o da autonomia, como condição de promover a independência para que a pessoa faça escolhas sem qualquer tipo de controle (Acosta, Gomes, Oliveira, Gomes \& Fonseca, 2017).

É importante ressaltar que há uma linha tênue no quesito empoderamento/autonomia, em que o enfermeiro deve ter cautela durante o seu trabalho, pois à medida que a mulher é empoderada, a mesma passa a reconhecer-se como vítima e reconhece o seu parceiro como agressor, podendo manifestar abruptamente reações contrárias as que o companheiro era habituado, incitando-o muitas vezes a condutas agressivas.

Dessa forma, é importante que as condutas em saúde voltadas ao manejo da violência contra a mulher sejam trabalhadas junto ao casal e de forma gradual, devendo-se priorizar a prevenção através da identificação precoce da violência psicológica, sem prejuízos aos serviços assistenciais quando essa e as demais formas de violência estiverem instaladas.

\subsection{Laicidade do Estado}

O princípio laicidade do Estado, traz que as políticas públicas voltadas para as mulheres devem ser formuladas e implementadas independentemente de princípios religiosos, de forma a assegurar os direitos consagrados na Constituição Federal 1988 e nos instrumentos e acordos internacionais assinados pelo Brasil.

É importante discutir nesse princípio a predominância e soberania masculina dentro das religiões, a iniciar pelo poder hierárquico que o homem possui na religião em detrimento de uma posição inferior da mulher na mesma religião. Aliado a isso, o Estado é predominantemente

HOLOS, Ano 36, v.5, e9609, 2020 
composto pela bancada religiosa e de homens, o que acaba por influenciar nas decisões que deveriam ser laicas.

A enfermagem, mesmo sendo uma profissão com predominância feminina, ainda sofre influências masculinas através da religião, que embasa essa profissão desde o seu surgimento, por meio das ações de caridade realizadas pelas Freiras nas Santas Casas de Misericórdia. Dessa forma, reflete-se a necessidade de uma assistência integral que ultrapasse as limitações impostas pelas religiões.

Então, é necessário considerar a dualidade pessoal-profissional do enfermeiro, trabalhando a desconstrução de preceitos auto impostos a ele em sua criação, sensibilizando-o enquanto pessoa para depois capacitá-lo. Isso porque, na maioria das vezes, a VCM é naturalizada pelo senso comum e faz parte da vida cotidiana do profissional enfermeiro, podendo interferir no atendimento, sobretudo em situações que o profissional acaba incentivando a passividade feminina mediante discursos de "tenha paciência" e ou "não bata de frente". Isso ocorre por conta da construção social, em que os conhecimentos e atos reconhecem essa submissão (Kim \& Motsei, 2002; Amarijo, 2017).

Segundo Nandi, Costa e Silva (2015), as lutas pelas conquistas das classes menos favorecidas, pelos seus direitos e pela a igualdade na priorização da construção de novas políticas são fortalecidas a partir dos grupos religiosos, movimentos eclesiais de base, organizações da sociedade civil e por grupos específicos que lutam por causas pontuais.

\subsection{Universalidade das Políticas}

O quinto princípio, a Universalidade das políticas, assevera que as políticas públicas devem garantir, em sua implementação o acesso aos direitos sociais, políticos, econômicos, culturais e ambientais para todas as mulheres.

O enfermeiro, mediante esse princípio, como gestor da Unidade Básica de Saúde é responsável pela garantia dos direitos acima citados. No entanto, ressalta-se que o mesmo requer apoio institucional, recursos humanos e materiais, bem como interesse e investimentos pelos gestores superiores, a fim de garantir o trabalho integral, multiprofissional e intersetorial.

Visto as sérias consequências, a VCM constitui-se como um considerável problema de saúde, que além de acarretar altos custos ao sistema de saúde, requer atendimento integral e humanizado prestado por equipe multiprofissional em rede. Isso demanda um conjunto de políticas articuladas que envolvem gestores e profissionais para o enfrentamento do problema em todo o território nacional, uma vez que apresenta inúmeras repercussões para a saúde e qualidade de vida das mulheres e suas famílias (Cortes et al., 2015; Silva et al., 2017).

Percebe-se que são poucos os gestores dos serviços de saúde que compreendem o enfrentamento da VCM como algo que faz parte do seu papel, e ainda menor o número deles que conhecem normas e leis ou protocolos de atuação. Por outro lado, sabe-se também da existência de gestores que aderem a esta perspectiva transformadora e daqueles que a rejeitam, favorecendo um retrocesso das políticas públicas (Batista, Schaiber \& Oliveira, 2018). 
Embora a decisão final de uma política pública ou tomada de decisão deva ser regulamentada pelo gestor, ela obrigatoriamente deve respeitar o interesse comum e a Constituição Federal, além disso, deve incluir a perspectiva de gênero voltada para relações de poder. Então a participação política, educação, cultura, saúde e diversidade devem estar entrelaçados com outros ministérios e instituições para que possam efetivar tais políticas. (Nandi, et al., 2015).

\subsection{Justiça Social}

O princípio da justiça social evidencia que a redistribuição dos recursos e riquezas produzidas pela sociedade e a busca de superação da desigualdade social, que atinge de maneira significativa às mulheres, deve ser assegurado.

No que concerne $o$ andamento das políticas formuladas e disponibilizadas para desenvolver a sensibilização da VCM e dos direitos humanos, parece haver um distanciamento entre o conhecimento e a prática o que dificulta essa igualdade. Vale salientar que não é no sentido das mulheres terem mais direitos mais sim de igualdade. Sendo que alguns desses entraves é o desconhecimento dos gestores com relação a coisas básicas como o conceito de gênero, como também a dimensionalidade entre masculino e feminino, levar em conta as diferenças sociais e culturais e compreendê-las como desigualdades de poder (Batista et al., 2018).

Considerada uma das principais conquistas dos movimentos feministas, a Convenção Interamericana para Prevenir, Punir e Erradicar a Violência Contra a Mulher, realizada em Belém do Pará em 1994, ampliou as considerações da Convenção de Viena, e influenciou novas políticas e estratégias de enfrentamento à violência de gênero. Em 1995, na China, foi realizada a IV Conferência Mundial sobre as Mulheres, identificando a violência contra a mulher como obstáculo ao alcance da igualdade e também como violação aos direitos humanos e as liberdades das mulheres (Cavalcanti \& Oliveira, 2017).

Sobre esse princípio, percebe-se que embora nos últimos anos tenha se dado uma maior atenção para a Violência Contra a Mulher, ainda há déficits em investimentos à nível intersetorial, a saber os setores da saúde, justiça, segurança e educação.

A luta do movimento feminista pelos direitos humanos das mulheres foi um dos principais contribuintes para o aumento significativo de serviços voltados para as mulheres em situação de violência no Brasil. Além do aumento da produção científica sobre o tema, surgimento de conselhos e coordenadorias da mulher, delegacias, serviços especializados e legislação específica (Cortes et al., 2015).

\subsection{Transparência dos atos públicos}

O princípio da transparência dos atos público, apresenta o respeito aos princípios da administração pública, tais como legalidade, impessoalidade, moralidade e eficiência, com transparência nos atos públicos e controle social, que deve ser garantido (Brasil, 2011). 
Reflete-se, nesse princípio, a transparência nos atos públicos tendo forte influência no que se refere à qualidade da assistência à saúde, mediante investimentos necessários. Além disso, destaca-se a impessoalidade presente desde as condutas dos gestores nacionais até as condutas do enfermeiro dentro da UBS. Assim, o Estado deve considerar as reais necessidades das vítimas acima dos dogmas dos gestores.

Algo que também merece atenção e está relacionado diretamente com a qualidade dos cuidados prestados às vítimas de violência se refere aos sentimentos e convicções pessoais do enfermeiro. Ou seja, o atendimento às diferentes situações torna-se difícil ao passo que suas crenças, valores, preconceitos podem interferir na sua postura ética e no julgamento profissional (Oliveira et al., 2015).

É preciso entender que há um distanciamento entre as leis, normas técnicas e suas realizações práticas, favorecendo assim o afastamento das mulheres ao acesso. Isso aponta para uma importante estratégia que é a educação em direitos humanos das mulheres como um dos mais importantes veículos de mudança cultural, como também o conhecimento e as ações dos gestores e profissionais da saúde, que são dependentes tanto do conhecimento quanto das motivações pessoais e culturais (Batista et al., 2018).

\subsection{Participação e Controle Social}

O último princípio diz respeito à participação e controle social, em que o debate e a participação das mulheres na formulação, implementação, avaliação e controle social das políticas públicas devem ser garantidos e ratificados pelo Estado brasileiro, como medida de proteção aos direitos humanos das mulheres e meninas (Brasil, 2011).

Nesse princípio pode-se discutir acerca do ciclo vicioso em que a mulher se encontra dentro da violência, no qual ela não se enxerga como vítima e acredita estar vivenciando experiências normais de uma relação amorosa. Dessa forma, se a mulher não possui conhecimento e autonomia sobre sua vida, a participação e o controle social referente à problemática da violência deve partir do incentivo do enfermeiro e de toda a equipe de saúde, assim como da comunidade, incluindo os manifestantes dos movimentos feministas, levando em consideração o artigo 196 da CF de 1988 que aborda o dever do Estado em garantir a saúde, não anulando o dever do indivíduo e comunidade.

Na perspectiva da Constituição Federal de 1988, após movimentos sociais vigorosos, foi proclamada: “(...) a igualdade entre os sexos no inciso 1 do artigo 5ㅇ, ao mesmo tempo em que insere no $\S 8$ o a garantia de assistência do Estado a todos os membros do grupo familiar, através da criação de mecanismos capazes de inibir a violência na esfera de suas relações" (Brasil, 1988; Sardenberg et al, 2010).

Ressalta-se que, antes dos movimentos feministas ganharem voz, as mulheres não tinham direito à vida pública e viviam exclusivamente para a manutenção do seu lar, nele incluído a dedicação ao marido e aos filhos. No que diz respeito à sexualidade, não tinha direito a seu corpo

HOLOS, Ano 36, v.5, e9609, 2020 
e ao prazer sexual e, caso apresentasse liberdade ou autonomia sobre tais aspectos era excluída e vista como anormal (Pinto, 2010).

Nesse contexto, o feminismo surgiu como um movimento libertário em que as mulheres lutam não só por seus direitos igualitários civis e sociais, mas pela autonomia de decidir sobre a sua vida e seu corpo. No Brasil, foi só a partir do final dos anos 1970, através de reivindicações das mulheres e da denúncia por parte dos movimentos feministas, que a violência contra a mulher passou a ser vista como um problema social (Pinto, 2010; Santos, 2016).

Assim, como resultado de anos de lutas feministas, a violência contra a mulher, atualmente, é uma questão reconhecida pela legislação nacional. Por se tratar de uma violação dos direitos humanos das agredidas, o fenômeno é um problema de saúde e segurança pública. Estudos acadêmicos e experiências de grupos e movimentos de mulheres têm mostrado que a violência contra a mulher, por se apresentar com um caráter de grande complexidade, abrange ampla gama de setores da sociedade, em que devem ser observadas questões que envolvem a justiça, assistência social, habitação, emprego e renda, educação, entre outros (Santos, 2016).

Reconhece-se a importância do enfermeiro em visualizar essa abrangência de setores sociais atrelados ao manejo correto da Violência Contra a Mulher durante sua assistência, evitando a redução da mulher apenas ao seu espaço socialmente imposto pelo patriarcado.

\section{CONSIDERAÇÃOES FINAIS}

Diante das reflexões realizadas pode-se perceber a relação dos princípios dessa política com a vivência do profissional de enfermagem, visto que o mesmo atua em diversos serviços de saúde e inclusive na APS onde ele tem maior oportunidade de estar próximo a essas mulheres.

Percebeu-se que esse profissional muito pode contribuir com a efetivação dessa política, tanto a partir das suas condutas assistenciais como também através da educação em saúde onde se pode criar um espaço favorável à troca conhecimento com grupos de homens e mulheres, constituindo espaços privilegiados fortalecendo as redes de apoio social a mulheres em situação de violência.

Nesse sentido, destacamos o quanto foi inovador fazer essa correlação entre os princípios da política, assistência à saúde e a literatura científica. Portanto, acredita-se que o estudo possa fomentar novas discussões e pesquisas acerca da problemática de enfrentamento da VCM.

\section{REFERÊNCIAS}

Acosta, D. F., Gomes, V. L. O., Oliveira, D. C., Gomes, G. C., \& Fonseca, A. D. (2017). Aspectos éticos e legais no cuidado de enfermagem às vítimas de violência doméstica. Texto \& Contexto Enfermagem. 26(3). Recuperado de https://www.redalyc.org/articulo.oa?id=71452267011. doi.org/10.1590/0104-07072017006770015 
Amarijo, C. L., de Oliveira Gomes, V. L., Gomes, A. M. T., da Fonseca, A. D., \& Silva, C. D. (2017). Representação social de profissionais de enfermagem acerca da violência doméstica contra a mulher: abordagem estrutural. Revista Enfermagem UERJ,25, 23648. Recuperado de https://www.e-publicacoes.uerj.br/index.php/enfermagemuerj/article/view/23648. doi.org/10.12957/reuerj.2017.23648

Batista, K. B. C., Schraiber, L. B., \& D’Oliveira, A. F. P. L. (2018). Gestores de saúde e o enfrentamento da violência de gênero contra as mulheres: as políticas públicas e sua implementação em São Paulo, Brasil. Cadernos de Saúde Pública, 34, e00140017. Recuperado de https://www.scielo.br/pdf/csp/v34n8/1678-4464-csp-34-08-e00140017.pdf. doi: 10.1590/0102-311X00140017

Cann, K. (2001). Violência doméstica: um levantamento comparativo dos níveis de detecção, conhecimento e atitudes em profissionais de saúde. Public Health, 115, (2), 89-95. Recuperado de https://www.scielo.br/scielo.php?pid=S0034-89102007000300021\&script=sci_arttext. https://doi.org/10.1590/S0034-89102007000300021

Cavalcanti, E. C. T., \& de Oliveira, R. C. (2019). Políticas públicas de combate à violência de gênero: a rede de enfrentamento à violência contra as mulheres. Revista de Pesquisa Interdisciplinar, 2(2). Recuperado de http://revistas.ufcg.edu.br/cfp/index.php/pesquisainterdisciplinar/article/view/194

Constituição da República Federativa do Brasil de 1988. Brasília. Recuperado de https://www2.senado.leg.br/bdsf/bitstream/handle/id/508200/CF88_EC85.pdf

Cordeiro, K. C. C., Santos, R. M., Gomes, N. P., Melo, D. S., Mota, R. S., \& Couto, T. M. (2015). Formação profissional e notificação da violência contra a mulher. Revista Baiana de Enfermagem29,(3), 209-217. recuperado de https://portalseer.ufba.br/index.php/enfermagem/article/view/13029. doi.org/10.18471/rbe.v29i3.13029

Cortes, L. F., Padoin, S. M., Vieira, L. B., Landerdahl, M. C., \& Arboit, J. (2015). Cuidar mulheres em situação de violência: empoderamento da enfermagem em busca de equidade de gênero. Revista Gaúcha de Enfermagem, 36, 77-84. Recuperado de https://www.scielo.br/pdf/rgenf/v36nspe/0102-6933-rgenf-36-spe-0077.pdf. doi.org/10.1590/1983-1447.2015.esp.57162

Garbin, C. A. S., Dias, I. D. A., Rovida, T. A. S., \& Garbin, A. J. Í. (2015). Desafıos do profıssional de saúde na notifıcação da violência: obrigatoriedade, efetivação e encaminhamento. Ciência \& Saúde Coletiva, 20, 1879-1890. Recuperado de https://www.scielo.br/scielo.php?pid=S1413$81232015000601879 \&$ script=sci_abstract\&tlng=pt. doi.org/10.1590/141381232015206.13442014 .

Gomes, M., Tavares, M. S., \& Sardenberg, C. B. (2010). A aplicação da Lei Maria da Penha em foco. Salvador: NEIM/UFBA. Recuperado de http://www.neim.ufba.br/wp/wpcontent/uploads/2019/08/violencia-de-genero-repositorio.pdf 
Kim, J.; Motsei, M . (2002). "Mulheres gozam de punição": atitudes e experiências de violência baseada em gênero entre enfermeiras da APS na área rural da África do Sul. Ciências Sociais e Medicina, 54, (8), 1243-1254. Recuperado de https://www.finersistemas.com/atenaeditora/index.php/admin/api/artigoPDF/28369

Lei $\mathrm{n}$ - 11.340, de 7 de agosto de 2006. Cria mecanismos para coibir a violência doméstica e familiar contra a mulher. Recuperado de http://www.planalto.gov.br/ccivil_03/_ato20042006/2006/lei/l11340.htm

Lira, K. F. S., \& de Barros, A. M. (2015). Violência contra as mulheres e o patriarcado: um estudo sobre o sertão de Pernambuco. Revista Ágora, (22), 275-297. Recuperado de https://periodicos.ufes.br/agora/article/view/13622

Marques, S. S., Riquinho, D. L., dos Santos, M. C., \& Vieira, L. B. (2017). Estratégias para identificação e enfrentamento de situação de violência por parceiro íntimo em mulheres gestantes. Revista Gaúcha de Enfermagem, 38(3). Recuperado de https://www.scielo.br/pdf/rgenf/v38n3/0102-6933-rgenf-38-3-e67593.pdf.

doi.org/10.1590/1983-1447.2017.03.67593

Menezes, P. R. D. M., Lima, I. D. S., Correia, C. M., Souza, S. S., Erdmann, A. L., \& Gomes, N. P. (2014). Enfrentamento da violência contra a mulher: articulação intersetorial e atenção integral. Saúde $e$ sociedade, 23, 778-786. Recuperado de https://www.scielo.br/pdf/sausoc/v23n3/0104-1290-sausoc-23-3-0778.pdf. doi 10.1590/S0104-12902014000300004

Nandi, A., Costa, T. J. \& Silva, A. S. (2015). Políticas Públicas de atendimento a mulheres vítimas de violência: A LEl. Revista Políticas Públicas \& Cidades, 2(1), 156-182. Recuperado de https://www.unaerp.br/revista-cientifica-integrada/edicoes-anteriores/volume-3-edicao4/2987-rci-os-servicos-de-saude-as-politicas-publicas-de-atendimento-as-mulheres-vitimasde-violencia-e-a-lei-maria-da-penha-06-2018/file

Oliveira, P. P., da Fonseca Viegas, S. M., dos Santos, W. J., da Silveira, A. A., \& Elias, S. C. (2015). Mulheres vítimas de violência doméstica: uma abordagem fenomenológica. Texto \& Contexto Enfermagem, 24(1), 196-203. Recuperado de https://www.scielo.br/pdf/tce/v24n1/pt_01040707-tce-24-01-00196.pdf. doi.org/10.1590/0104-07072015002900013

Organização Pan-americana de Saúde. Organização Mundial de Saúde. (2012). Prevenção da violência sexual e da violência por parceiro íntimo contra a mulher: ação e produção de evidência. Recuperado de https://apps.who.int/iris/bitstream/handle/10665/44350/9789275716359_por.pdf;jsessioni $\mathrm{d}=32 \mathrm{D} 2829 \mathrm{FBDA6A36E38B2FEF2F1E3CB08}$ ? sequence $=3$

Pinto, C. R. J. (2010). Feminismo, história e poder. Revista de Sociologia Política, 18, (36), 15-23. Recuperado de https://www.scielo.br/pdf/rsocp/v18n36/03.pdf

Plano Nacional de Políticas para as Mulheres. (2013). Brasília: Secretaria de Políticas para as Mulheres, pp114.

Recuperado de 
http://www.mulheres.ba.gov.br/arquivos/File/Publicacoes/PlanoNacionaldePoliticasparaas Mulheres20132015.pdf

Portaria no 198/GM/MS, de 13 de fevereiro de 2004. Institui a Política Nacional de Educação Permanente em Saúde como estratégia do Sistema Único de Saúde para a formação e o desenvolvimento de trabalhadores para o setor e dá outras providências. Diário Oficial da União. Recuperado http://bvsms.saude.gov.br/bvs/saudelegis/gm/2014/prt0278_27_02_2014.html

Santos, C. R. (2016). Movimento Social no Enfrentamento da Violência contra a Mulher: a experiência de um grupo de trabalho em Salvador e Região Metropolitana/BA. Revista Feminismos, 4(1). Recuperado de https://portalseer.ufba.br/index.php/feminismos/article/view/30211

Secretaria Nacional de Enfrentamento à Violência contra as Mulheres. (2011). Secretaria de Políticas para as Mulheres - Presidência da República. Política Nacional de Enfrentamento à Violência Contra as Mulheres. Recuperado de https://www12.senado.leg.br/institucional/omv/entenda-a-violencia/pdfs/politica-nacionalde-enfrentamento-a-violencia-contra-as-mulheres

Silva, N. N. F., Leal, S. M. C., Trentin, D., de Oliveira Vargas, M. A., Vargas, C. P., \& Vieira, L. B. (2017). Atuação dos enfermeiros da atenção básica a mulheres em situação de violência. Enfermagem em Foco, 8(3). Recuperado de http://revista.cofen.gov.br/index.php/enfermagem/article/view/1290

Sousa, A. R. D., Gomes, N. P., Estrela, F. M., Paixão, G. P. D. N., Pereira, Á., \& Couto, T. M. (2018). Violência conjugal: discursos de mulheres e homens envolvidos em processo criminal. Escola Anna Nery, 22(1). Recuperado de https://www.scielo.br/scielo.php?pid=S141481452018000100204\&script=sci_abstract\&tlng=pt. doi.org/10.1590/2177-9465-ean-20170108

Vieira, R. H. G., Erdmann, A. L., \& Andrade, S. R. D. (2013). Vacinação contra influenza: construção de um instrumento educativo para maior adesão dos profissionais de enfermagem. Texto \& Contexto-Enfermagem, 22(3), 603-609. https://www.scielo.br/pdf/tce/v22n3/v22n3a05.pdf

Visetin, F. (2015). A enfermagem na atenção primária ao cuidar de mulheres em situação de violência de gênero. Invest. educ. enferm., 33, (3), 556-564. Recuperado de http://www.scielo.org.co/scielo.php?pid=S0120-

53072015000300020\&script=sci_arttext\&tlng=pt. doi.org/10.17533/udea.iee.v33n3a20

Zuchi, C. Z., Silva, E. B. D., Costa, M. C. D., Arboit, J., Fontana, D. G. R., Honnef, F., \& Heisler, E. D. (2018). Violência contra as mulheres: concepções de profissionais da Estratégia Saúde da Família acerca da escuta. REME rev. min. enferm, e-e. Recuperado de https://www.scielo.br/pdf/rbedu/v24/en_1809-449X-rbedu-24-e240002.pdf. doi.org/10.1590/S1413-24782019240002 


\section{COMO CITAR ESTE ARTIGO:}

Feitosa, F. E. A., Magalhães, B. DE C., Alcantara, P. P. T. DE. (2020). Reflexões acerca dos princípios da Política Nacional de Enfrentamento à Violência contra as Mulheres e sua correlação com a atuação do Enfermeiro. Holos. 36(5), 1-13.

\section{SOBRE OS AUTORES}

\section{F. E. A. FEITOSA}

Bacharel em Enfermagem pela URCA. E-mail: franciscaeaf@hotmail.com

ORCID ID: https://orcid.org/0000-0003-0420-0977

\section{B. DE C. MAGALHÃES}

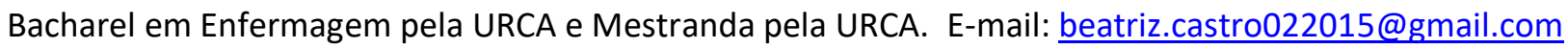
ORCID ID: https://orcid.org/0000-0002-6827-6359

\section{P. P. T. DE ALCANTARA}

Bacharel em Enfermagem pela URCA e Mestre em Desenvolvimento Regional Sustentável pela UFCA. Email: enfermeira.tavares.81@gmail.com

ORCID ID: https://orcid.org/0000-0003-3337-4845

Editor(a) Responsável: Francinaide de Lima Silva Nascimento Pareceristas Ad Hoc: Isabella Campos e Guélmer Faria

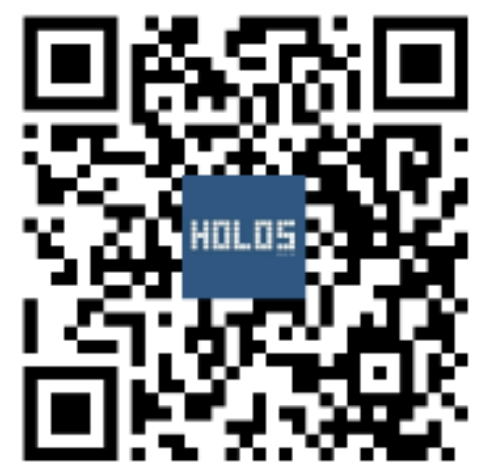

